Original article

\title{
Collectins and galectins in the abomasum of goats susceptible and resistant to gastrointestinal nematode infection
}

\author{
Bárbara M.P.S. Souza ${ }^{\mathrm{a}, *}$, Sabrina M. Lambert ${ }^{\mathrm{a}}$, Sandra M. Nishi ${ }^{\mathrm{a}}$, Gustavo F. Saldaña ${ }^{\mathrm{b}}$, \\ Geraldo G.S. Oliveira $^{\mathrm{c}}$, Luis S. Vieira ${ }^{\mathrm{d}}$, Claudio R. Madruga ${ }^{\mathrm{a}}$, Maria Angela O. Almeida ${ }^{\mathrm{a}}$ \\ ${ }^{a}$ Laboratory of Cellular and Molecular Biology, School of Veterinary Medicine and Animal Science, Federal University of Bahia, Salvador, BA, Brazil \\ ${ }^{\mathrm{b}}$ Institute for Research on Genetic Engineering and Molecular Biology (INGEBI-CONICET), Laboratory of Molecular Biology of Chagas Disease, Buenos Aires, Argentina \\ ${ }^{\mathrm{c}}$ Laboratory of Cellular and Molecular Immunology, Research Center of Gonçalo Muniz, Fiocruz, BA, Brazil \\ ${ }^{\mathrm{d}}$ National Research Center of Goats and Sheep, Embrapa, Sobral, CE, Brazil
}

\section{A R T I C L E I N F O}

\section{Keywords:}

Innate immunity

Lectins

Helminth

Ruminants

PCR

\begin{abstract}
A B S T R A C T
Originally described in cattle, conglutinin belongs to the collectin family and is involved in innate immune defense. It is thought that conglutinin provides the first line of defense by maintaining a symbiotic relationship with the microbes in the rumen while inhibiting inflammatory reactions caused by antibodies leaking into the bloodstream. Due to the lack of information on the similar lectins and sequence detection in goats, we characterized the goat conglutinin gene using RACE and evaluated the differences in its gene expression profile, as well as in the gene expression profiles for surfactant protein A, galectins 14 and 11, interleukin 4 and interferongamma in goats. We used Saanen and Anglo Nubian F2 crossbred goats monitored over a period of four months and characterized them as resistant (R) or susceptible (S) based on the average values of EPG counts. Goat conglutinin was similar to bovine conglutinin, but its gene expression varied among different tissues. However, as with bovine conglutinin, it was most highly expressed in the liver. Variation in conglutinin $(\mathrm{R}=24.3 \pm 3.9$; $\mathrm{S}=23.5 \pm 2.6, \mathrm{p}=0.059)$, protein surfactant $\mathrm{A}(\mathrm{R}=23.8 \pm 5.2, \mathrm{~S}=24.4 \pm 2.3, \mathrm{p}=0.16)$, galectin 14 $(\mathrm{R}=15.9 \pm 3.5, \quad \mathrm{~S}=14.7 \pm 6.2, \mathrm{p}=0.49)$ and galectin 11 gene expression $(\mathrm{R}=25.4 \pm 2.6$, $\mathrm{S}=25.8 \pm 3.7, \mathrm{p}=0.53$ ) was not significant between groups. However, there were weak correlations between interleukin 4 and the protein surfactant A gene $(r=0.459, p=0.02)$ and between interleukin 4 and galectin $11(r=0.498, p=0.01)$. Strong correlation between interferon-gamma and galectin $14(r=0.744$, $\mathrm{p}=0.00$ ) was observed. Galectin 14 was negatively correlated with the number of nematodes in the goat $(r=-0.416, p=0.04)$ as well as the EPG count $(r=-0.408, p=0.04)$. This is the first study to date that identifies the gene expression of conglutinin, surfactant protein A and galectins 14 and 11 in the goat abomasum. In conclusion, we present evidence that lectin is involved in the immune response to gastrointestinal nematodes, which suggests that collectins and galectins are involved in the molecular recognition of helminths.
\end{abstract}

\section{Introduction}

Gastrointestinal nematode (GIN) infections are one of the main factors that lead to low performance and economic loss in goat herds. Goats, compared with sheep, have different grazing behaviors and a less effective immune response in reducing the number of nematode larvae and expelling the adults (Hoste et al., 2010). Host immune mechanisms against gastrointestinal nematodes are complex and depend on numerous genes (Garside et al., 2000). Individuals who are genetically resistant to Haemonchus contortus present eosinophilia, mucosal mastocitosis and high IgA and IgG levels (Gill et al., 1994, 2000). At the gastrointestinal surface, epithelial cells produce molecules that are secreted in the mucus and contribute to localized immune responses. Among these molecules, lectins such as galectins and collectins, which are produced by various types of animal cells and may be important in controlling parasites, interact with oligosaccharide structures present on the surface of pathogens (Drickamer and Taylor, 1993; Perrigoue et al., 2008; Van De Wetering et al., 2004a,b).

The galectin family members, galectin 14 and 15, bind glycans on the surface of potentially pathogenic microorganisms and act as recognition and effector factors in innate immunity (Vasta, 2009). These proteins were identified in the abomasal tissue of sheep following

\footnotetext{
* Corresponding author at: Laboratório de Biologia Celular e Molecular, Escola de Medicina Veterinária e Zootecnia, Universidade Federal da Bahia (UFBA), Av Adhemar de Barros 500 - Ondina, Salvador, BA 40.170-110, Brazil.

E-mail address: bparana@ufba.br (B.M.P.S. Souza).
} 
exposure to $H$. contortus (Dunphy et al., 2002). Collectins are a family of calcium-dependent defense lectins in animals. There have been nine collectin family members defined so far, of which, mannan binding lectin (MBL), surfactant proteins (SP-A and SP-D) and conglutinin (CGN) are the best characterized (Hansen and Holmskov, 1998; Veldhuizen et al., 2011). The binding of collectins to microorganisms may facilitate microbial clearance through aggregation, complement activation, opsonization and phagocytosis activation. In addition, the collectins can modulate inflammatory response and the adaptive immune system (Van De Wetering et al., 2004a,b).

Conglutinin is a protein in the collectin family that is involved in the innate immune defense, showing antiviral and antibacterial activity (Drickamer, 1992). This protein interacts with the complement system to bind carbohydrates on the degradation product, iC3b (Laursen et al., 1994), and stimulates the oxidative burst in phagocytes (Dec and Wernicki, 2012). In this study, we characterize the conglutinin gene in goats and evaluate differences in the gene expression profiles of conglutinin, surfactant protein A, galectin 14 and 11, interleukin 4 and interferon gamma in goats monitored over a four-month period who were characterized as resistant or susceptible based on their average EPG count values.

\section{Materials and methods}

\subsection{Goat conglutinin characterization}

\subsubsection{Animals tissue}

Samples of the abomasum, large intestine, lung, liver and spleen were collected from one Anglo-Nubian and Saanen crossbred goat, male, approximately 12 months old. The tissues were aliquoted and stored in RNA stabilizer solution (RNAlater ${ }^{\circledR}$, Applied Biosystems, Foster City, CA, USA) and maintained at $-80^{\circ} \mathrm{C}$ until RNA extraction.

\subsection{2. $R T-P C R$}

For the RNA extraction, 50-100 mg fragments of tissue frozen with liquid nitrogen were ground with a mortar and pestle and homogenized in Trizol reagent (Invitrogen, USA). RNA concentration was estimated by fluorimetry (Qubit, Invitrogen, USA), and the quality was assessed by agarose gel electrophoresis. After DNase treatment, cDNA was synthetized using Superscript III RT (Invitrogen, USA) with Oligo(dT) ${ }_{12-18}$ primers and RNase inhibitors according to the manufacturers recommendations.

PCR was conducted with a final volume of $20 \mu \mathrm{L}$ using PCR buffer $(1 \times), 2.0 \mathrm{mM} \mathrm{MgCl} 2,0.2 \mathrm{mM}$ of each dNTP, 5 pmol of each primer (COLBOV-R and COLBOV-F), $1 \mathrm{U}$ Taq DNA Platinum (Invitrogen, Carlsbad, USA) and $100 \mathrm{ng}$ of cDNA. The cycling conditions were $94^{\circ} \mathrm{C}$ for $2 \mathrm{~min}$, followed by 35 amplification cycles at $92{ }^{\circ} \mathrm{C}$ for $1 \mathrm{~min}, 60^{\circ} \mathrm{C}$ for $1 \mathrm{~min}$ and $72{ }^{\circ} \mathrm{C}$ for $1 \mathrm{~min}$ and a final extension step at $72{ }^{\circ} \mathrm{C}$ for $7 \mathrm{~min}$. The presence of PCR inhibitors in the cDNA samples was excluded by amplifying a fragment of the GAPDH (glyceraldehyde-3phosphate dehydrogenase) gene. After electrophoresis, all PCR products were viewed in a $2 \%$ agarose gel containing Sybr Gold (Invitrogen, Carlsbad, USA) by transillumination with a UV light.

\subsubsection{Race}

Bovine conglutinin sequences (D14085, L1887.1) obtained from GenBank were used as reference for the design of primers GSP1 (5'ACA CTG GCC AAC GGC TGT ACC CTG GTT $-3^{\prime}$ ) and GSP2 (5'- ACC CAC TCC TCC TTT GGG CCC AGG TTC T $-3^{\prime}$ ), targeting the amplification of the carboxyl terminal end. The amplification reaction was performed on the RNA samples from the goat abomasum using the GeneRacer $^{\circledR}$ kit and the SuperScript and TOPO TA Cloning ${ }^{\circledR}$ Kit for Sequencing (Invitrogen). The products were measured by agarose gel electrophoresis and purified with Wizard ${ }^{\circledR}$ SV Gel and PCR Clean-Up (Promega). The product was cloned into pGEMT (Promega) following the manufacturer's recommendations. Ligation products were transformed into chemically competent $E$. coli TOP10 cells, and transformants were selected with ampicillin $(50 \mu \mathrm{g} / \mathrm{ml})$. After confirmation by sequencing, construct pGEMT-CGN was extracted by alkaline lysis and purified with PEG8000 (Sambrook et al., 2001).

\subsubsection{Identification and analysis}

Plasmids of the selected clones were submitted for capillary sequencing (Macrogen, Inc.), and a similarity analysis of the inserted DNA and the deduced protein sequence was conducted using BLASTN, BLASTp and Transeq. Open readings frame (ORF) predictions were obtained using http://www.expasy.org/tools/. Sequence alignment was measured using Clustal W and Bioedit software. Phylogenetic diagrams were constructed by calculating the proportion difference (pdistance) of the aligned amino acid sites from full-length peptide sequences (including the goat bovine - CGN Capra hircus) using the maximum likelihood method and MEGA5 software.

\subsection{Expression profiles of the lectins and cytokines}

\subsubsection{Experimental design}

Animals were selected from a herd of 172 goats, F2 generation from $1 / 2$ Anglo-nubiana $\times 1 / 2$ Saanen, raised at Embrapa Experimental Unit Goats and Sheep (Unidade Experimental da Embrapa Caprinos e Ovinos), Sobral, Ceará in Northeast Brazil (latitude $3^{\circ} 42^{\prime} 59.01^{\prime \prime}$ and longitude $\left.40^{\circ} 23^{\prime} 21.57^{\prime \prime}\right)$. Animals of both genders aged between four and five months were placed in the experimental area of an irrigated pasture with Tanzania grass (Panicum maximum Jacq. Cv. Tanzania) naturally contaminated by nematode larvae.

At the beginning of the experiment, all animals were dewormed with four different chemical groups: Closantel (10 mg/ $\mathrm{kg} \mathrm{BW}$ ), Ivermectin $(0.2 \mathrm{mg} / \mathrm{kg})$, Levamisole $(7.5 \mathrm{mg} / \mathrm{kg})$ and Moxidectin $(0.2 \mathrm{mg} / \mathrm{kg})$. The animals were monitored using eggs per gram of feces (EPG) counts (Ueno and Gonçalves, 1998) until the count was zero. After that, the animals were transferred to the Tanzania grass pasture naturally contaminated with nematode larvae (Haemonchus sp., Trichostrongylus sp. and Oesophagostomum sp.). The individual fecal samples were examined weekly, and the number of nematode EPG counts were determined for each animal as previously described by Gordon and Whitlock (1939) and modified by Ueno and Gonçalves (1998). When the mean EPG reached 800, blood and fecal samples were collected over three days, and the animals were dewormed again with the same anthelmintics. Animals were subjected to a second challenge when the fecal EPG count was zero, to discriminate different levels of resistance to the parasitic infection (Coutinho et al., 2015).

During the experimental period, the EPG count distribution among the herd showed a negative binomial pattern that allowed the animals with the phenotypic traits of susceptibility (mean $\mathrm{EPG}=2237 \pm 1043)$ or resistance $(\mathrm{EPG}=655 \pm 235)$ to be identified. Ten animals from the first group and 14 animals from the second were selected for abomasal tissue analysis. Identification of Strongyloidea larvae in the fecal cultures revealed Haemonchus as the predominant genus, followed by Trichostrongylus and Oesophagostomum. The animals were euthanized and necropsied to recover the total content of the abomasum. The animals in the susceptible group presented more parasites $(444 \pm 209)$ than the resistant group (126 \pm 47$)$. All specimens of parasites observed in abomasum belonged to the species Haemonchus contortus. Abomasal samples were preserved in Eppendorftype tubes containing RNAlater (Applied Biosystems, USA) and kept in a freezer at $-80^{\circ} \mathrm{C}$.

All animal procedures were performed in accordance with and approved by the Animal Ethics Committee, School of Veterinary Medicine, Federal University of Bahia, Brazil.

\subsubsection{Real time $P C R$}

Eight sets of primers were used to evaluate the expression of the following genes: beta-actin ( $\beta$-actin) and GAPDH (endogenous 
Table 1

Primer sequences used for RT-qPCR and respective references or Genbank Access number.

\begin{tabular}{|c|c|c|c|c|}
\hline Gene & Primer & Oligonucleotides & Size product & GenBank/reference \\
\hline \multirow[t]{2}{*}{ GAPDH } & GAPDH-F & 5'-TGACGAGCTTCCCGTTCTCT-3' & 79 & AF272837 \\
\hline & GAPDH-R & 5'ATGGTCTACATGTTCCAGTATGATTCC-3' & & \\
\hline \multirow[t]{2}{*}{ Conglutinin (CGN) } & COLBOV-F & 5'-GAGAATGAGGCCGTGACACA-3' & 85 & KF130969 \\
\hline & COLBOV-R & 5'-ACCTCCCCTCCGTGGAGAT-3' & & \\
\hline \multirow[t]{2}{*}{ Surfactant protein A (SPA) } & SP-A-F & 5'-CTGCCTGCTGATGAACACATT-3' & 113 & KF130970 \\
\hline & SP-A-R & 5'-GCATGTCAAGGTGCTTGGTGTA-3' & & \\
\hline \multirow[t]{2}{*}{ Galectin 14 (Gal14) } & Gal14-F & 5'-GTAACACGATGCAGCTAGGAAAC-3' & 84 & Robinson et al., 2011 \\
\hline & Gal14-R & 5'-AGATCTGAAACAGACTCСССТTCT-3' & & \\
\hline \multirow[t]{2}{*}{ Galectin 11 (Gal11) } & Gal11-F & 5'-CATTCCATTCCGTTTCTGGTACT-3' & 83 & Robinson et al., 2011 \\
\hline & Gal11-R & 5'-CTTTCTCTTCCTTCTGCCAACTC-3' & & \\
\hline \multirow[t]{2}{*}{ Interleukin 4 (IL-4) } & IL-4-F & 5'-GGAGCTGCCTGTAGCAGACG-3' & 51 & Hein et al., 2010 \\
\hline & IL-4-R & 5'-TTCTCAGTTGCGTTCTTTGGG-3' & & \\
\hline \multirow[t]{2}{*}{ Interferon gama (IFN $\gamma$ ) } & IFNG-F & 5'-ATCTCTTTCGAGGCCGGAGA-3’' & 51 & Lacroux et al., 2006 \\
\hline & IFNG-R & 5'ATTGCAGGCAGGAGAACCAT-3' & & \\
\hline
\end{tabular}

controls), CGN and SPA (collectins), Gal14 and Gal11 (galectins) and IL- 4 and IFN- $\gamma$ (cytokines) (Table 1). Due to the lack of information on goat collectins in the literature, bovine mRNA sequences were selected from GenBank and used for the primer design through the Primer Express Program (Applied Biosystems). The high similarity between bovine conglutinin, CL-43 and CL-46 coding regions, did not allow the selection of specific primers for each gene; therefore, CGN primers recognizing a conserved region, common to those three genes were tested on the goat samples. The amplicons produced by conventional PCR on goat cDNA using the designed primer for CGN and SPA were sequenced, and they showed $92 \%$ and $100 \%$ identity to the bovine cDNA sequences, respectively.

For the RNA extraction, 50-100 mg fragments of liquid nitrogen frozen tissue were ground with a mortar and pestle and homogenized in Trizol reagent (Invitrogen, USA). RNA concentration was estimated by fluorimetry (Qubit, Invitrogen, USA), and the quality was assessed by agarose gel electrophoresis. After DNase treatment, cDNA was synthetized using Superscript III RT (Invitrogen, USA) with Oligo(dT) ${ }_{12-18}$ primers and RNase inhibitors following the manufacturer's recommendations.

Real-time PCR was carried out using the abomasal tissue cDNA as a template. All samples were tested in duplicate with $100 \mathrm{ng}$ of cDNA and 10 pmol of each specific primer using GoTaq qPCR (Promega USA) in a final volume of $20 \mu \mathrm{L}$. Product amplification was detected by fluorescent signal after each extension step and analyzed by 7500 Software version 2.0.3 (Applied Biosystems). PCR efficiency was assessed for each gene by testing serial dilutions of the template, and the CT values were used for the linear regression analysis and for calculating the coefficient of determination $\left(\mathrm{R}^{2}\right)$ (Bustin et al., 2009). Gene expression was quantified by using the $\Delta \mathrm{CT}$ method $(\Delta \mathrm{CT}=$ target gene $\mathrm{CT}-$ endogenous control CT), and the relative values were normalized against an arbitrary number of 20 (Pfaffl, 2006).

All RT-qPCR reactions were submitted to a dissociation curve analysis confirming the production of one single peak, indicating an absence of nonspecific products during the amplification reaction.

For gene expression quantification, two different housekeeping genes were tested as endogenous controls. The GAPDH results were more stable and consistent than those of the $\beta$-actin, showing no significant difference $(p=0.67)$ between the susceptible $(25.87 \pm 2.95)$ and resistant $(26.41 \pm 3.29)$ groups.

\subsubsection{Statistical analysis}

Statistical differences in gene expression between the resistant and susceptible groups were assessed using one-way ANOVA and the Pearson-r test for correlation analysis (SPSS v. 17.0, IBM, USA). Differences were considered significant when $\mathrm{p}<0.05$.

\section{Results}

\subsection{Goat conglutinin characterization}

The full-length cDNA encoding goat conglutinin consists of a 282-bp 5 -non-coding region, followed by a 1107 -bp sequence with an open reading frame encoding a polypeptide of 368 amino acids with a predicted molecular mass of $37.6 \mathrm{kD}$ including start and stop codons and a 488-bp 3'-non-coding region including a poly(A) tail (Fig. 1). The deduced amino acid sequence reveals a protein with 368 amino acids and an $85 \%$ similarity to bovine conglutinin (GenBank Accession number P23805, NP78630.2, CAA50665.1). The signal peptide consists of 20 amino acids, an $\mathrm{N}$-terminal domain of 25 amino acids with two cysteine residues and a collagen-like domain formed by 56 repetitions of glycine-X-Y, where $\mathrm{X}$ and $\mathrm{Y}$ can be any amino acid. The helicoidal $\alpha$-neck region contains 28 amino acids and a CRD with 127 amino acids presenting a similar sequence to the collectins, demonstrating residues for carbohydrate ligation and Ca dependence $\left(\mathrm{E}^{332}, \mathrm{~N}^{335}, \mathrm{E}^{343}, \mathrm{~N}^{355}, \mathrm{D}^{356}\right)$. The goat sequence showed differences at the collagen-like domain represented by the amino acid deletions at $\mathrm{P}^{154}, \mathrm{~S}^{155}$ and $\mathrm{G}^{156}$ observed in the bovine sequences (Accession Number P23805).

BLAST analysis revealed strong similarities to bovine conglutinin, CL43 and CL4 and the highest match index with ovine conglutinin (Fig. 2). The differential transcription of conglutinin's mRNA was detected by RT-PCR in the liver, in the lung and abomasum, and in downregulation in spleen and large intestine. No transcription was detected in the small intestine, lymph nodes or kidneys.

\subsection{Lectins and cytokines gene expression}

Gene expression in the galectin and collectins was observed in all goat abomasal samples. There was no statistically significant difference in expression between the resistant and susceptible groups for gene expression in CGN $(\mathrm{R}=24.3 \pm 3.9 ; \mathrm{S}=23.5 \pm 2.6, \mathrm{p}=0.059)$, $\mathrm{SPA} \quad(\mathrm{R}=23.8 \pm 5.2, \quad \mathrm{~S}=24.4 \pm 2.3, \quad \mathrm{p}=0.16), \quad$ Gal14 $(\mathrm{R}=15.9 \pm 3.5, \quad \mathrm{~S}=14.7 \pm 6.2, \quad \mathrm{p}=0.49) \quad$ or $\quad$ Gal11 $(\mathrm{R}=25.4 \pm 2.6, \mathrm{~S}=25.8 \pm 3.7, \mathrm{p}=0.53$ ) (Fig. 3 ).

In the correlation analysis, the Gal14 gene expression levels were negatively correlated with abomasal parasite burden $(r=-0.416$, $\mathrm{p}=0.04)$ and EPG $(\mathrm{r}=-0.408, \mathrm{p}=0.04)$, and were positively correlated with IFNG $(\mathrm{r}=0.744, \mathrm{p}=0.00)$. IL4 gene expression levels were positively correlated with SPA $(r=0.459 ; \mathrm{p}=0.02)$, GAL11 $(\mathrm{r}=0.498 ; \mathrm{p}=0.01)$ and IFNG $(\mathrm{r}=0.594 ; \mathrm{p}=0.02)$.

\section{Discussion}

Conglutinin was originally described in cattle (Van De Wetering et al., 2004a,b). However, serological tests using anti-bovine polyclonal 
gttacaggacaggtataaggagccagttctcgcccaggaactctaatttgcctggacgt ggttacaggacaggtataaggagccagttctcgcccaggaactctaatttgcctggacgt gctagagccctgcaggaaacaactatagcgctgcagactccagccctagcctgtccagag

5 untranslated sequence I. $\overline{\text { cagcaagtgagaggaaacaagccagcattgtaagaggacatgcttctcctccctctctcc }}$ $M \quad L \quad L \quad L \quad P \quad L \quad S$ signal peptide I

$\overline{\text { gtgctgcccetgctcacacagccetggagatccetgggagcagaaatgacgttctattcc }}$ $\begin{array}{lllllllllllllllllllll}V & L & P & L & L & T & Q & P & W & R & S & L & G & A & E & M & T & F & Y & S\end{array}$ N-terminal domain $\overline{\text { totaccctggttatgtagccccccggagggtggettg }}$

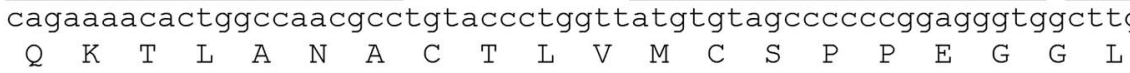
cctggtcgtgatggacgagatgggagagaaggcccccggggagagaagggagatccaggt $\begin{array}{llllllllllllllllllllllll}P & G & R & D & G & R & D & G & R & E & G & P & R & G & E & K & G & D & P & G\end{array}$

tcaccaggacctgcaggacgagcagggaggcctggaccagctggccctattgggccgaaa $\begin{array}{lllllllllllllllllllll}S & P & G & P & A & G & R & A & G & R & P & G & P & A & G & P & I & G & P & K\end{array}$

ggagacaatggctctgctggagaacctggaccaaagggagacactggaccacctgggcet $\begin{array}{llllllllllllllllllll}G & D & N & G & S & A & G & E & P & G & P & K & G & D & T & G & P & P & G & P\end{array}$

$\overline{\text { ccaggtatgcctggtccagctggaagagagggcccctcagggaggcaggggagcatggga }}$ $\begin{array}{lllllllllllllllllllllll}P & G & M & P & G & P & A & G & R & E & G & P & S & G & R & Q & G & S & M & G\end{array}$ collagen-like domain

cctccaggcacaccaggccccaaaggagaacctgggcccaaaggaggagtgggtggccca $\begin{array}{lllllllllllllllllllll}P & P & G & T & P & G & P & K & G & E & P & G & P & K & G & G & V & G & G & P\end{array}$

$\overline{\text { ggcatgcagggctccccaggtctcaaaggagagagaggtgcacccggggagattggagcc }}$ $\begin{array}{lllllllllllllllllllll}G & M & Q & G & S & P & G & L & K & G & E & R & G & A & P & G & E & I & G & A\end{array}$

cctggacgtgctggggcagcagggcetgctggagccataggtccacaggggccttcaggt

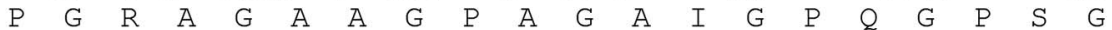

$\overline{\text { gccaggggccccccaggactgaagggggacagaggtactcctggagaaagaggagaaaag }}$ $\begin{array}{lllllllllllllllllllll}A & R & G & P & P & G & L & K & G & D & R & G & T & P & G & E & R & G & E & K\end{array}$

ggtgagagtgggcttgcagaggtcaatgctctcaggcagcgggtgacaatcttagaggga $\begin{array}{llllllllllllllllllll}G & E & S & G & L & A & E & V & N & A & L & R & Q & R & V & T & I & L & E & G\end{array}$ $\alpha$-helical neck domain

catctgcgacgcttccagaatgcttctctcagtataagaag $\overline{\text { ggtgctcttccetgat }}$ $\begin{array}{llllllllllllllllllll}\mathrm{H} & \mathrm{I} & \mathrm{R} & \mathrm{R} & \mathrm{F} & \mathrm{Q} & \mathrm{N} & \mathrm{A} & \mathrm{F} & \mathrm{S} & \mathrm{Q} & \mathrm{Y} & \mathrm{K} & \mathrm{K} & \mathrm{A} & \mathrm{V} & \mathrm{L} & \mathrm{F} & \mathrm{P} & \mathrm{D}\end{array}$

ggccaggctgtcagggagaagattttcaagatggcaggtgtggtcaatcatattcagat $\begin{array}{llllllllllllllllllll}G & Q & A & V & R & E & K & I & F & K & M & A & G & V & V & K & S & Y & S & D\end{array}$

gcccagcagctctgcacagaggctaagggacagctggcctccccacgctctgcagccgag

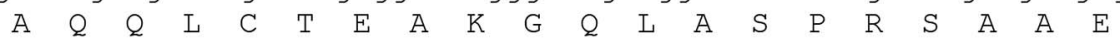

aatgaggccgtgacacagctggccagagcccacaagagaatgcttacctgagcatgaat $\begin{array}{lllllllllllllllllllll}N & E & A & V & T & Q & L & A & R & A & H & K & E & N & A & Y & L & S & M & N\end{array}$ carbohydrate recognition domain

$\overline{\text { gacatctccacggaggggaggttcacctaccccagtggggaaatactggtctattccaac }}$

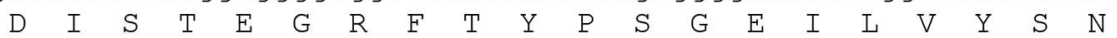

$\overline{\text { tgggccagtggggagcccaacaacagcaatgatggacaaccagagcactgtgtggaaatc }}$ $\begin{array}{lllllllllllllllllllllll}W & A & S & G & E & P & N & N & S & N & D & G & Q & P & E & H & C & V & E & I\end{array}$

tatcctgagggcaagtggaatgacataccctgcagtgagcaacgcctcgtgatctgcgag

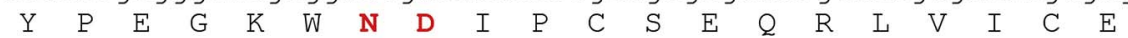
I 3'untranslated region

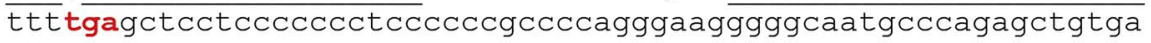
$\mathrm{F}$

gctgccaacatcccaataaaaggtgactgtctgctgctcacggcttccccactgagcca cgggataaggccacaaggcaggcctcctatgtaactcctccctcagaataaaggttgaaa ctggcaaaaaaaaaaaaaaaaaaaaaaaaa 


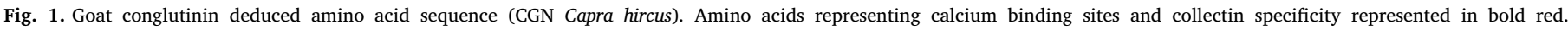

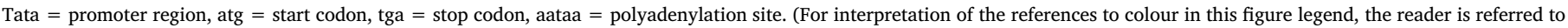
the web version of this article.)

and monoclonal antibodies reacted with lectins in goat, sheep and swine serum, suggesting the presence of conglutinin in these species (Dec et al., 2011). A comparative analysis of different collectins demonstrated high similarity to bovine conglutinin, but differed in the deletion of three amino acid residues at the collagen domain. Homologies on the CRD domain indicate specificity to mannose and Ca-dependent sites (Veldhuizen et al., 2011) suggesting that similar functional abilities are preserved.

High conglutinin expression was detected in the liver, followed by lung and abomasal tissue, and lower expression was detected in the spleen and large intestine, with a similar distribution in bovine tissues (Barik et al., 2014; Lim et al., 1993). Holmskov et al. (1992) showed bovine conglutinin in dendritic cells, macrophages and endothelial cells. Per these authors, this distribution pattern may indicate the possible functional activity of the protein recognizing carbohydrate residues on microorganism surfaces to support the antigen presentation and phagocytosis. However, Barik et al. (2014) observed that the quaternary structure of the protein in goats, sheep, and cattle differs from that of wild ruminants, suggesting a probable variation in the efficiency of antimicrobial activity among these species.

Galectin and collectin gene expression were detected in all 24 goat samples, indicating active production of conglutinin, surfactant proteinA and galectins 14 and 11 in the abomasal site. Similar results had previously only been described in bovine and ovine species (Dunphy et al., 2000; Hoorens et al., 2011; Li and Gasbarre, 2009; Li et al., 2010; Robinson et al., 2011).

Collectin gene expression has been associated with gastrointestinal nematode infections in studies with Cooperia oncophora and Ostertagia ostertagi, and in both studies there was stimulation of these lectins in the abomasum and small intestine, respectively (Li and Gasbarre, 2009; Li et al., 2010), suggesting it may be a recognition molecule of the nematode cell surface in ruminants (Li and Gasbarre, 2009).

Galectin was first described as being induced in the abomasal mucosa of sheep infected with Haemonchus contortus and was immunolocalized in the upper layer of the epithelium (Dunphy et al., 2000). This molecule modifies the properties of mucosal adhesion, promoting it as a response to infection with $H$. contortus (Robinson et al., 2011; Young et al., 2009), and it was recently detected during a proteomic analysis with variation in the abomasal mucosa after infection with Teladorsagia circumcincta (Athanasiadou et al., 2008). Recently, in vitro studies on recombinant galectin-11 showed that the protein significantly inhibited the development and growth of L4 larvae in $H$. contortus, indicating the potential role of any galectin in mediating resistance against helminth parasite infections and a new immune mechanism targeting the L4 stage, and possibly the adult stage, of helminth growth (Preston et al., 2015).

The GIN distribution pattern can be explained by differences in the individual ability to acquire and express immunity that are genetically controlled and variable between breeds and individuals (Kassai and Sreter, 1992; Stear and Wakelin, 1998). This diversity has been reported by Amarante et al. (2004) and Bassetto et al. (2009) where resistant animals tolerated the effects of a helminth infection and produced less pasture contamination, reducing the frequency of vermifugations and delaying the onset of anthelmintic resistance. However, there are few studies that demonstrate the mechanisms of the immune response underlying these differences.

In this study, expression of the CGN, SPA, Gal14 and Gal11 genes was not significantly different between the resistant and susceptible groups. This lack of variation may be due to the similar handling conditions and the chronicity of infection, since these goats were exposed to constant infection, which stimulates the immune system and balances the host-parasite dynamics. Li and Gasbarre (2009)

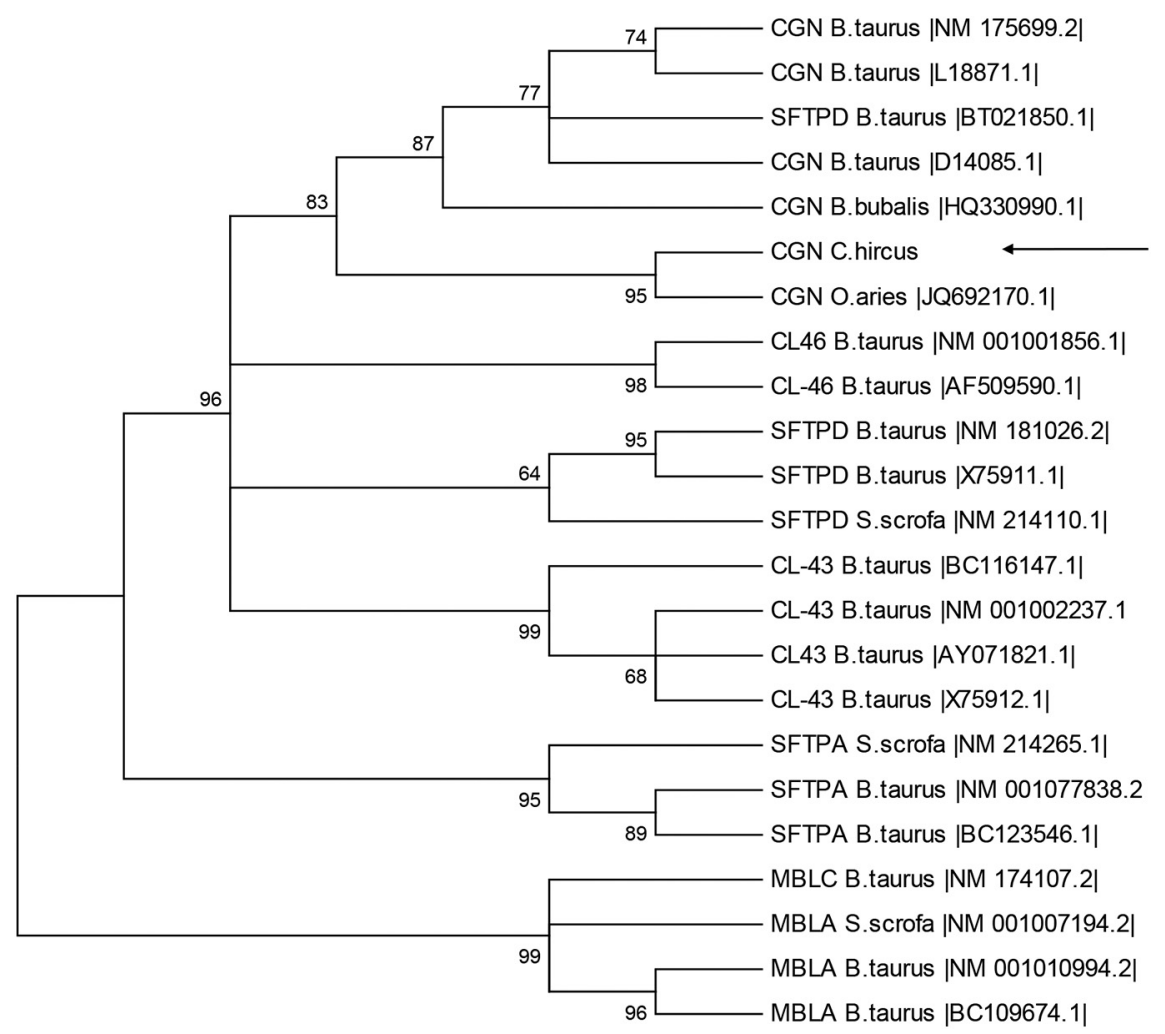

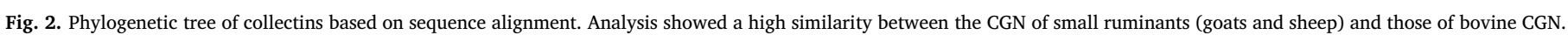


COLBOV

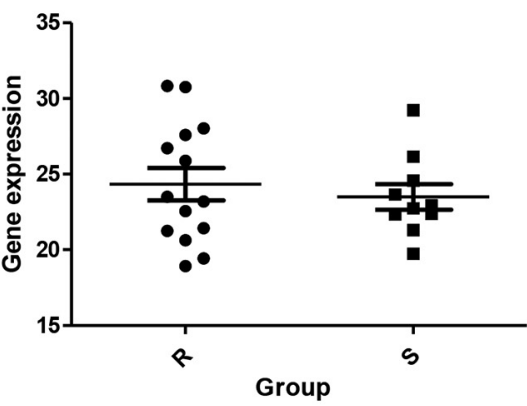

Gal14

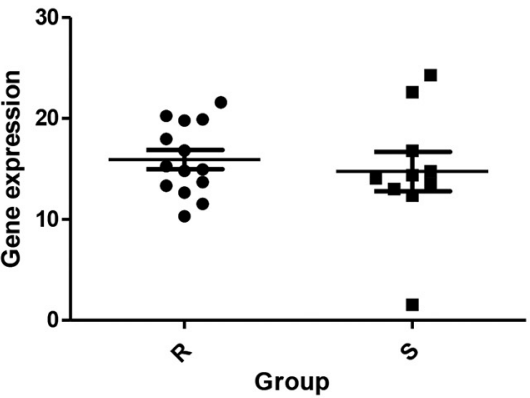

IL4

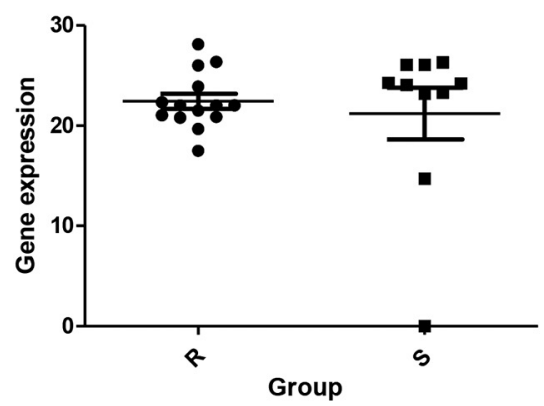

SPA

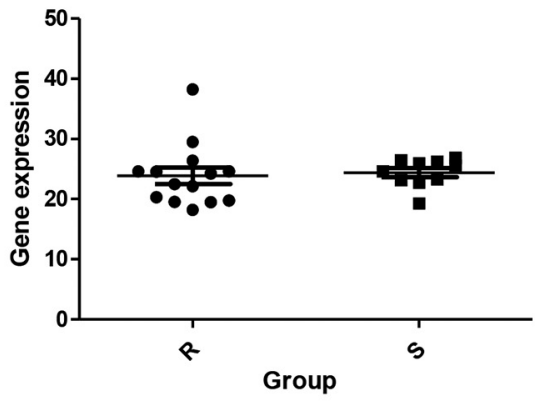

Gal11

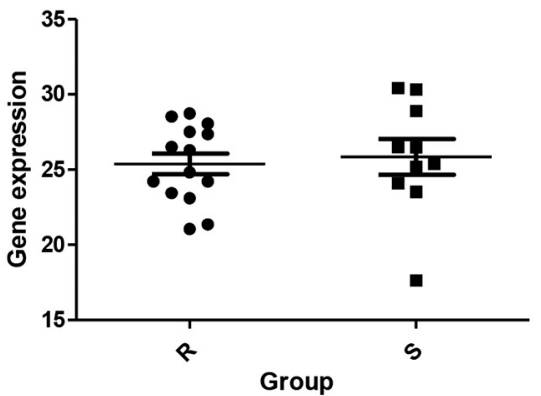

IFNG

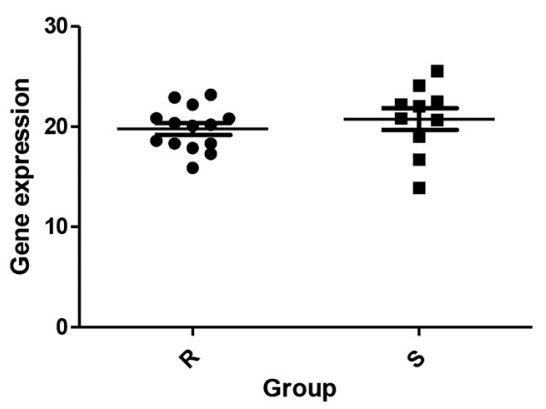

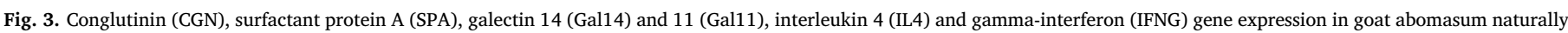
infected with gastrointestinal nematodes, classified as resistant (R) or susceptible (S) using parasitological data.

demonstrated different patterns of galectin and collectin gene expression induced at different moments of infection with $C$. oncophora, activating the gene on the 14 th day of infection, reaching a peak at day 28 and decreasing at day 42 .

Interestingly, Gal14 was negatively correlated with nematode numbers $(r=-0.416, p=0.04)$ and EPG counts $(r=-0.408$, $\mathrm{p}=0.04$ ), perhaps because of its direct immunomodulatory action, the establishment of infection, or its affinity to lacto-N-neotetraose, an oligosaccharide expressed by helminths (Young et al., 2009). Recently, presence of this galectin was also noted in the gastrointestinal tract mucus of sheep under parasite challenge by $H$. contortus, as well as its expression in the cytoplasm and nucleus of sheep eosinophils (Robinson et al., 2011; Young et al., 2009), reinforcing its role in the control of parasites.

Surprisingly, Gal14 is strongly correlated with IFNG $(=0.744$, $\mathrm{p}=0.00$ ), and it is thought that this ratio is due to the connection with galectin 9 , a member of the galectin family described as chemotactic to eosinophils and induced by IFNG (Imaizumi and Kumagai, 2002). The Gal9 may be stimulated by IFNG, resulting in an inflammatory response, and it recruits eosinophils during the degranulation process, which releases the Gal14.

There was no statistical association between the lectin gene expression assessed in this study and nematode infection. Increased Gal14 gene expression was negatively correlated with the parasite findings, suggesting that it directly affects the parasites, and the remaining markers act indirectly as immunomodulators (Hoorens et al., 2011; Pemberton et al., 2012). The correlation between IL4 and SPA $(\mathrm{r}=0.459, \mathrm{p}=0.02)$ and between that and GAL11 $(\mathrm{r}=0.498$, $\mathrm{p}=0.01$ ), suggests that these proteins can alter the expression of IL4 after exposure to the parasite.

IL4 and IFNG were also positively correlated $(r=0.594, p=0.02)$, indicating that both responses can be induced in the same environment during infection by gastrointestinal nematodes. Although the Th2 pattern of cytokines, characterized by IL4, IL5 and IL13 induction, is 
dominant in animals that are resistant to nematode infection, the activation pathways and effector mechanisms involved in this polarization are not completely understood and vary considerably between hosts (Lacroux et al., 2006; Pernthaner et al., 2000).

\section{Conclusion}

Based on these results, we conclude that conglutinin is not specific to cattle, and due to the gene expression pattern, the protein might have the same functional features in other species. The gene expression of bovine collectin, surfactant protein A and galectins 14 and 11 was identified in the abomasum of goats infected with gastrointestinal nematodes. Lectin gene transcription was accompanied by activation of IL4 and IFNG genes; however, there was no association between lectin gene expression to susceptibility and resistance to nematode infection. Abomasal expression of collectins and galectins in goats can be induced in response to gastrointestinal nematodes, suggesting a possible role in immune recognition and defense.

\section{Conflict of interest statement}

The authors declare no conflicts of interest.

\section{Acknowledgements}

This work was supported by Fundação de Amparo à Pesquisa do Estado da Bahia (FAPESB), and BS was a recipient of a PhD scholarship from Coordenação de Aperfeiçoamento de Pessoal de Nível Superior (CAPES). Preliminary results were presented as an abstract at the 27th Brazilian Congress of Veterinary Parasitology, Brazil, September 2012.

\section{References}

Amarante, A.F.T., Bricarello, P.A., Rocha, R.A., Gennari, S.M., 2004. Resistance of Santa Ines, Suffolk and Ile de France sheep to naturally acquired gastrointestinal nematode infections. Vet. Parasitol. 120 (1-2), 91-106.

Athanasiadou, S., Pemberton, A., Jackson, F., 2008. Proteomic approach to identify candidate effector molecules during the in vitro immune exclusion of infective Teladorsagia circumcincta in the abomasum of sheep. Vet. Res. 39 (58), 1-16.

Barik, S., Sidappa, C.M., Saini, M., Doreswamy, R., Das, A., Sharma, A.K., Gupta, P.K., 2014. Sequence-based appraisal of the genes encoding neck and carbohydrate recognition domain of conglutinin in blackbuck (Antilope cervicapra) and goat (Capra hircus). BioMed. Res. Int. 2014.

Bassetto, C.C., Silva, B.F., Fernandes, S., Amarante, A.F.T., 2009. Contaminação da pastagem com larvas infectantes de nematóides gastrintestinais após o pastejo de ovelhas resistentes ou suscetíveis à verminose. Rev. Bras. Parasitol. Vet. 18 (4), 63-68.

Bustin, S.A., Benes, V., Garson, J.A., Hellemans, J., Huggett, J., Kubista, M., Mueller, R. Nolan, T., Pfaffl, M.W., Shipley, G.L., Vandesompele, J., Wittwer, C.T., 2009. The MIQE guidelines: minimum information for publication of quantitative real-time PCR experiments. Clin. Chem. 55 (4), 611-622.

Coutinho, R.M.A., Benvenuti, C.L., Júnior, A.L.F.D.A., Silva, F.C., Neves, M.R.M., Navarro, A.M.D.C., Vieira, L.D.S., Zaros, L.G., 2015. Phenotypic markers to characterize F2 crossbreed goats infected by gastrointestinal nematodes. Small Rumin. Res. 123 (1), 173-178.

Dec, M., Wernicki, A., Puchalski, A., Urban-Chmiel, R., 2011. Conglutinin is not specific to cattle. Vet. Med. 56 (10), 510-519.

Drickamer, K., 1992. Engineering galactose-binding activity into a C-type mannosebinding protein. Nature 360, 183-186.

Drickamer, K., Taylor, M., 1993. Biology of animal lectins. Annu. Rev. Cell Biol. 9, 237-264.

Dunphy, J.L., Balic, A., Barcham, G.J., Horvath, A.J., Nash, A.D., Meeusen, E.N., 2000 Isolation and characterization of a novel inducible mammalian galectin. J. Biol. Chem. 275, 32106-32113.
Garside, P., Kennedy, M.W., Wakelin, D., Lawrence, C.E., 2000. Immunopathology of intestinal helminth infection. Parasite Immunol. 22 (12), 605-612.

Gill, H.S., Husband, A.J., Watson, D.L., Gray, G.D., 1994. Antibody-containing cells in the abomasal mucosa of sheep with genetic resistance to Haemonchus contortus. Res. Vet. Sci. 56 (1), 41-47.

Gill, H.S., Altmann, K., Cross, M.L., Husband, A.J., 2000. Induction of T helper 1- and T helper 2-type immune responses during Haemonchus contortus infection in sheep. Immunology 99 (3), 458-463.

Gordon, H., Whitlock, H.V., 1939. A new technique for counting nematode eggs in sheep faeces. J. Council Sci. Ind. Res. 12, 50-52.

Hansen, S., Holmskov, U., 1998. Structural aspects of collectins and receptors for collectins. Immunobiology 199 (2), 165-189.

Hein, W.R., Pernthaner, A., Piedrafita, D., Meeusen, E.N., 2010. Immune mechanisms of resistance to gastrointestinal nematode infections in sheep. Parasite Immunol. 32 (8), 541-548.

Holmskov, U., Teisner, B., Pedersen, N.T., Laursen, S.B., Rasmussen, H.B., Jensenius, J.C., 1992. Tissue localization of conglutinin, a bovine C-type lectin. Immunology 76 (1), 169-173.

Hoorens, P., Rinaldi, M., Mihi, B., Dreesen, L., Grit, G., Meeusen, E., Li, R.W., Geldhof, P., 2011. Galectin-11 induction in the gastrointestinal tract of cattle following nematode and protozoan infections. Parasite Immunol. 33, 669-678.

Hoste, H., Sotiraki, S., Landau, S.Y., Jackson, F., Beveridge, I., 2010. Goat nematode in teractions: think differently. Trends Parasitol. 26, 376-381.

Imaizumi, T., Kumagai, M., 2002. Interferon-gama stimulates the expression of galectin-9 in cultured human endothelial cells. J. Leukoc. Biol. 72, 486-491.

Kassai, T., Sreter, T., 1992. Genetic aspects of the host resistance to helminthic infections. Res. Rev. Parasitol. 52, 67-75.

Lacroux, C., Nguyen, T., Andreoletti, O., Françoise, P., Grisez, C., Bergeaud, J.P., Gruner L., Brunel, J.C., François, D., Dorchies, P., 2006. Haemonchus contortus (Nematoda: Trichostrongylidae) infection in lambs elicits an unequivocal Th2 immune response. Vet. Res. 37, 607-622.

Li, R.W., Gasbarre, L.C., 2009. A temporal shift in regulatory networks and pathways in the bovine small intestine during Cooperia oncophora infection. Int. J. Parasitol. 39, 813-824.

Li, R.W., Hou, Y., Li, C., Gasbarre, L.C., 2010. Localized complement activation in the development of protective immunity against Ostertagia ostertagi infections in cattle. Vet. Parasitol. 174, 247-256.

Lim, B.L., Lu, J., Reid, K.B., 1993. Structural similarity between bovine conglutinin and bovine lung surfactant protein D and demonstration of liver as a site of synthesis of conglutinin. Immunology 78 (1), 159-165.

Pemberton, A.D., Brown, J.K., Craig, N.N., Pate, J., Mclean, K., Inglis, N.F., Knox, D., Knight, P.A., 2012. Changes in protein expression in the sheep abomasum following trickle infection with Teladorsagia circumcincta. Parasitology 139 (3), 375-385.

Pernthaner, A., Cole, S., Morrison, L., Green, R., Shaw, R.J., Hein, W.R., 2000. Cytokine and antibody subclass responses in the intestinal lymph of sheep during repeated experimental infections with the nematode parasite Trichostrongylus colubriformis. Vet. Immunol. Immunopathol. 114, 135-148.

Perrigoue, J.G., Marshall, F.A., Artis, D., 2008. On the hunt for helminths: innate immune cells in the recognition and response to helminth parasites. Cell. Microbiol. 10 (9), 1757-1764.

Pfaffl, M., 2006. Relative quantification. In: Dorak, T. (Ed.), Real-time PCR. International University Line, pp. 63-82.

Preston, S.J.M., Beddoe, T., Walkden-Brown, S., Meeusen, E., Piedrafita, D., 2015. Galectin-11: a novel host mediator targeting specific stages of the gastrointestinal nematode parasite, Haemonchus contortus. Int. J. Parasitol. 45 (12), 791-796.

Robinson, N., Pleasance, J., Piedrafita, D., Meeusen, E.N., 2011. The kinetics of local cytokine and galectin expression after challenge infection with the gastrointestinal nematode Haemonchus contortus. Int. J. Parasitol. 41, 487-493.

Stear, M., Wakelin, D., 1998. Genetic resistance to parasitic infection. Ver. Sci. Tech. 17, 143-153.

Ueno, H., Gonçalves, P.C., 1998. Manual para diagnóstico das helmintoses de ruminantes, 4 ed. Japan International Cooperation Agency, Tókio (143p).

Van De Wetering, J.K., Van Remoortere, A., Vaandrager, A., Batenburg, J.J., Van Golde, L.M.G., Hokke, C.H., Van Hellemond, J.J., 2004a. Surfactant protein D binding to terminal alpha1-3-linked fucose residues and to Schistosoma mansoni. Am. J. Respir. Cell Mol. Biol. 31 (5), 565-572.

Van De Wetering, J.K., Van Golde, L.M.G., Batenburg, J.J., 2004b. Collectins: players of the innate immune system. Eur. J. Biochem. FEBS 271 (7), 1229-1249.

Veldhuizen, E.J.A., Van Eijk, M., Haagsman, H.P., 2011. The carbohydrate recognition domain of collectins. FEBS J. 278 (20), 3930-3941.

Young, A.R., Barcham, G.J., Kemp, J.M., Dunphy, J.L., Nash, A., Meeusen, E.N., 2009. Functional characterization of an eosinophil-specific galectin, ovine galectin-14. Glycoconjug. J. 26 (4), 423-432. 